\title{
Efeitos do Carregamento de Impacto em Perfis Soldados de Aço
}

\author{
Luís G. C. Andrade ${ }^{1}$, Ivan Guerra Machado ${ }^{1}$ \\ 1 Universidade Federal do Rio Grande do Sul - UFRGS, Laboratório de Soldagem \& Técnicas Conexas, Programa de \\ Pós-graduação em Engenharia de Minas, Metalúrgica e Materiais - PPGE3M, Porto Alegre, RS, Brasil.
}

Recebido: 29 Nov., 2017

Aceito: 24 Jan., 2018

E-mails: engenharia.solda@gmail.com (LGCA), welder@ufrgs.br (IGM)
Este é um artigo publicado em acesso aberto (Open Access) sob a licença Creative Commons Attribution Non-Commercial, que permite uso, distribuição e reprodução em qualquer meio, sem restrições desde que sem fins comerciais e que 0 trabalho original seja corretamente citado.
Resumo: Os efeitos do carregamento de impacto em membros estruturais como vigas não possuem um consenso em regras, códigos de projeto e padrões. Geralmente a análise é baseada em conceitos de fadiga ou estática e testes de energia absorvida no impacto ou tenacidade realizados em corpos de prova relativamente pequenos. Assim, o principal objetivo deste estudo foi comparar o comportamento teórico e experimental de vigas quando submetidas ao carregamento de impacto. Para tanto, oito vigas soldadas de aço (perfis " $\mathrm{T}$ " e "I") foram engastadas (soldadas) em ambas extremidades e testadas. Para avaliar o desempenho de cada viga, foi medida a deflexão e dureza do metal de solda e alma da viga. Dentre outras conclusões, notou-se que metal base e metal de solda demonstraram comportamento similar, do ponto de vista de ductilidade.

Palavras-chave: Vigas soldadas; Carregamento de impacto; Aço estrutural.

\section{Effects of Impact Loading on Steel Welded Profiles}

\begin{abstract}
Effects of impact loading on structural members like beams are still not a generalized concern in rules, codes and standards. Usually the analysis is based on static or fatigue concepts, and toughness or impact absorbed energy tests on relatively small specimens. So, the main aim of this study was to compare theoretical and experimental beams behaviour when subjected to impact loading. Therefore, eight structural welded steel beams ( $T$ - and I-profiles) were clamped (welded) on both ends and tested. To evaluate the performance of each beam, it was measured its deflection and hardness of weld metal and web. Among other facts, it was noticed that weld and base metals have shown similar behaviour as far as ductility is concerned.
\end{abstract}

Key-words: Welded beams; Impact loading; Structural steel.

\section{Introdução}

Dentre inúmeras aplicações das estruturas metálicas, pode-se citar: telhados, edifícios industriais, residenciais e comerciais, pontes e viadutos, pontes rolantes, reservatórios, torres, guindastes, silos e fornecem uma solução rápida e econômica para os casos mais diversos de construção mecânica e montagem. Em alguns casos, estas estruturas podem ser submetidas à solicitações dinâmicas com intensidade suficiente para causar deformação permanente, levando ao colapso local ou total. Entretanto, aços estruturais (aços ferríticos) demonstram um comportamento na fratura que não pode ser deduzido de um simples ensaio de tração. Fatores como concentração de tensão, baixa temperatura e altas taxas de deformação podem culminar em ductilidade inferior ao indicado no ensaio de tração [1,2].

Em estruturas soldadas de maior porte (edifícios, galpões, pontes entre outros), normalmente é desejada a capacidade de resistir à danos sem que ocorra falha, e ainda permanecer operacional. Isto depende da energia que a estrutura pode absorver. Quando uniões soldadas estão presentes, este parâmetro não é mais governado pelas propriedades do metal base unicamente, mas pelas características da junta na condição como soldada [3].

Em estudos prévios realizados por Parkes [4] e Mentel [5] sobre vigas submetidas a impacto, os valores experimentais de deflexão obtidos situavam-se entre 30 e $80 \%$ dos valores previstos. Symonds e Bodner [6], em estudo semelhante, também obtiveram resultados com grande dispersão e com deflexões nos experimentos de aproximadamente $60 \%$ do valor teórico previsto. Nestes estudos atribuiu-se essa variação ao efeito de sensibilidade à taxa de deformação, aumentando a tensão de escoamento durante a deformação. 
Assim, este estudo visa determinar a relação entre uma abordagem matemática simplificada e a resposta real de uma viga ao impacto estrutural, avaliando dois perfis metálicos, com dois comprimentos através da deflexão da viga e perfil de dureza no metal de solda e alma da viga.

\section{Materiais e Métodos}

Todos os ensaios foram realizados de modo a garantir a repetibilidade com o mínimo de variação nas condições de teste. Os itens 2.1 a 2.3 fornecem dados sobre a confecção dos CP's e suas propriedades e os itens 2.4 e 2.5 informações sobre os ensaios.

\subsection{Metal base}

As vigas foram construídas a partir de chapas de aço ASTM A-36, sendo as vigas "curtas" (comprimento de $420 \mathrm{~mm}$ ) e espessura de 4,75 mm e as vigas "longas" (comprimento de $1.000 \mathrm{~mm}$ ) e espessura de 6,35 mm. Suas respectivas composição química, propriedades mecânicas [7] e propriedades de seção, são mostradas na Tabela 1, Tabela 2 e Figura 1, respectivamente. Amostras para o ensaio de tração foram extraídos no sentido de laminação da chapa de acordo com [8]. As regiões com durezas distintas na Figura 1 serão discutidas na seção 3.2.

Tabela 1. Composição química em \% do aço ASTM A-36.

\begin{tabular}{ccccccc}
\hline & C & Mn & P & S & Si & Cu \\
ASTM A-36 & 0,25 & $\ldots$ & 0,030 & 0,030 & 0,40 & 0,20 \\
Chapa 4,75 mm & 0,16 & 1,03 & 0,030 & 0,014 & 0,018 & 0,01 \\
Chapa 6,35 mm & 0,10 & 0,47 & 0,024 & 0,014 & 0,026 & 0,01 \\
\hline
\end{tabular}

Todos os valores especificados pela norma são máximos, com exceção do Cu que é valor mínimo, quando solicitado; “..." significa que não há requisito pela norma. Fonte: ASTM A-36 / A-36M [7].

Tabela 2. Propriedades mecânicas do aço ASTM A-36.

\begin{tabular}{cccc}
\hline & Tensão de Escoamento [Mpa] & Limite de Resistência [Mpa] & Alongamento em 50 mm [\%] \\
ASTM A-36 & 250 & $400-550$ & 21 \\
Chapa 4,75 mm & 280 & 439 & 32 \\
Chapa 6,35 mm & 261 & 452 & 29 \\
\hline Fon
\end{tabular}

Fonte: ASTM A-36 / A-36M [7].
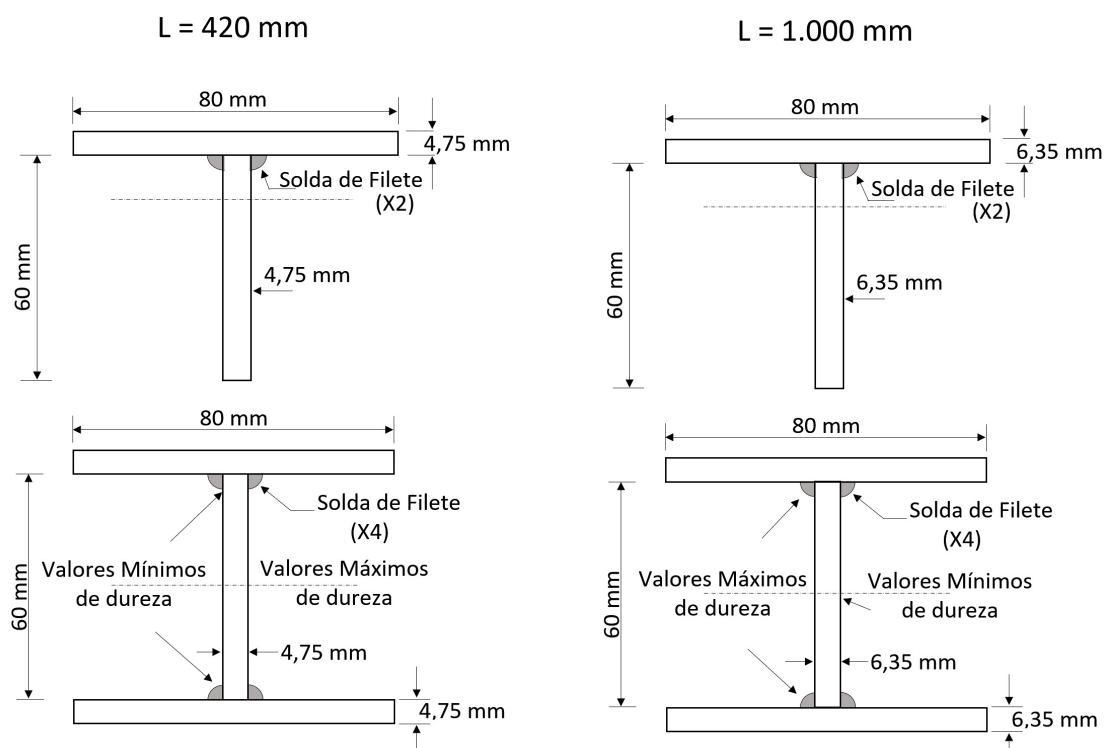

Figura 1. Seções transversais das vigas adotadas nos ensaios. 


\subsection{Procedimento de soldagem}

As vigas "T" e "I" foram soldadas na posição plana, através do processo GMAW. O gás de proteção utilizado foi uma mistura de $75 \%$ Ar e $25 \% \mathrm{CO}_{2}$, com fluxo de $16 \mathrm{l} / \mathrm{min}$. Todos os cordões de solda foram depositados com ângulo de trabalho de $0^{\circ}$ e $15^{\circ}$ de deslocamento, com distância bico de contato - peça ("stick out") de $18 \mathrm{~mm}$. Foi adotado um manipulador com controle numérico de modo a automatizar a soldagem.

O metal de adição utilizado foi arame AWS ER 70S-6, com $\varnothing 1,2 \mathrm{~mm}$ [9-11]. O consumível adotado, por ter resistência semelhante ao metal base é considerado "matching". Cada cordão de solda foi depositado ininterruptamente, aguardando-se o metal base resfriar até $50^{\circ} \mathrm{C}$ antes de iniciar a soldagem do lado oposto da junta. A temperatura foi controlada por termômetro infravermelho.

Os parâmetros de soldagem adotados foram: Tensão de 27,1 V; Corrente de 270 A; 8,3 mm/s de velocidade de deslocamento e $8 \mathrm{~m} / \mathrm{min}$ de velocidade de alimentação do arame. Tais parâmetros foram obtidos experimentalmente e visam garantir a integridade da junta soldada e evitar descontinuidades [12], especialmente falta de fusão ou de penetração.

\subsection{Caracterização das juntas soldadas}

A Figura 2 mostra representativamente o perfil de dureza obtido através do cordão de solda, executado com 2.000 gf de carga e tempo de identação de 10 segundos [13]. Também mediu-se a dureza na alma da viga, para auxiliar a prever o fluxo de escoamento.

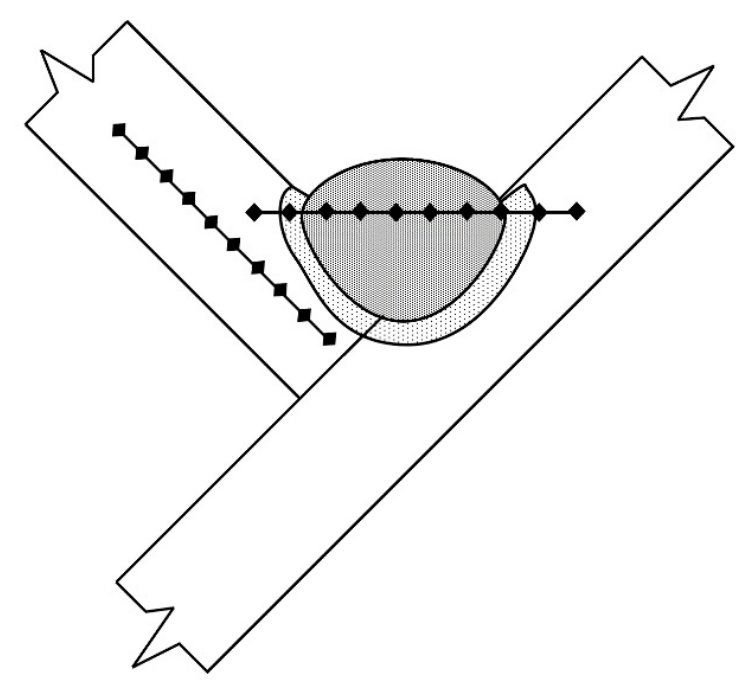

Figura 2. Perfil de medição de dureza executado.

\subsection{Momento de escoamento vs. momento plástico}

A resistência de uma viga de proporções comuns é determinada pelo momento fletor máximo que esta pode resistir. Vigas de materiais dúcteis (aço estrutural ou alumínio) normalmente não fraturam sob carregamento estático, mas sim falham por deflexão excessiva [14,15]. Para tais vigas, quando construídas com seções relativamente espessas para impedir flambagem local, o momento fletor máximo é aquele que causa escoamento plástico através da seção. Este momento máximo, ou momento "plástico", é normalmente chamado de $\mathrm{M}_{\mathrm{p}}$ e pode ser calculado pela Equação 1.

$$
M_{p}=\sigma_{y} \cdot Z
$$

onde $\sigma_{y}$ correponde à tensão de escoamento (mínima) do material e Z (módulo plástico da seção) é a soma aritmética dos momentos estáticos com relação ao eixo neutro plástico [15,16]. Deve-se notar que o momento plástico é sempre superior ao momento requerido para submeter a fibra mais externa à tensão de escoamento. Este momento, chamado de $\mathrm{M}_{\mathrm{y}}$ é dado pela Equação 2: 


$$
M_{y}=\frac{I \cdot \sigma_{y}}{c}
$$

onde "I" é o segundo momento de área (ou momento de inércia) e "c" é a distância do eixo neutro até a fibra mais distante. Assim, o fator de forma, é dado pela relação $M_{p} / M_{y}$ na Equação 3.

$$
\frac{M_{p}}{M_{y}}=\frac{Z}{I / c}
$$

\subsubsection{Falha sob cisalhamento}

Em vigas I e seções similares com alma delgada a compressão diagonal que acompanha o cisalhamento pode levar à uma falha por flambagem, e em vigas de ferro fundido ou concreto a tração resultante que similarmente acompanha o cisalhamento pode causar ruptura. A equação para tensão de cisalhamento (Equações 4 e 5), esta última assumindo que a alma resista à todo esforço cortante $(\mathrm{V})$ ) pode ser considerada válida enquanto as tensões nas fibras do material não ultrapassem o limite de proporcionalidade - que é o ponto onde ocorre o afastamento da linearidade na curva tensão - deformação: o material entra em regime plástico. Assim sendo, ela pode ser empregada para calcular o cisalhamento vertical necessário que resultará em falha em qualquer caso onde o limite último de resistência ao cisalhamento da viga é atingido, enquanto as tensões onde ocorre este cisalhamento máximo ainda estejam dentro do limite de proporcionalidade [14,17].

A tensão de cisalhamento, particularmente próximo às extremidades ou então ao local de aplicação da carga pontual, desempenha um papel importante, maior ainda em carregamentos dinâmicos do que em estáticos [18].

Uma viga I ou membro com alma delgada pode falhar por flambagem na alma devido à compressão diagonal quando o cisalhamento atinge determinado valor. Em vigas I leves este tipo de flambagem ocorre quando a tensão de cisalhamento $(\tau)$, calculada por:

$$
\tau=1,25 \mathrm{~V} / \text { Área da alma }
$$

ou

$$
\tau=V / \text { Área da alma }
$$

atinge um valor igual à carga unitária suportada por uma seção vertical da viga, como uma coluna - também chamada de carga crítica de Euler [18,19]. Para vigas com alma delgada, a seção pode ser calculada como uma coluna de Euler; para vigas pesadas deve-se adotar uma equação parabólica ou outra adequada.

\subsubsection{Tensões dominantes}

Como 90 a $98 \%$ da tensão de cisalhamento é suportada pela alma de uma viga [15], é importante conhecer seu valor e para qual comprimento ela representa uma tensão governante. A tensão de cisalhamento independe do comprimento da viga (para carregamento pontual no centro da viga), e varia através da seção transversal (Figura 3 e Equação 4) [14,15]. Deve-se notar que estes valores ocorrem no eixo neutro da viga, como mostrado na Figura 3.

Ao assumir-se que:

$$
\begin{aligned}
& \tau=\frac{V Q}{I b} \\
& \sigma_{y}=\frac{M_{y} \cdot c}{I} \\
& M_{y}=\frac{P . L}{8} \\
& V=P / 2
\end{aligned}
$$



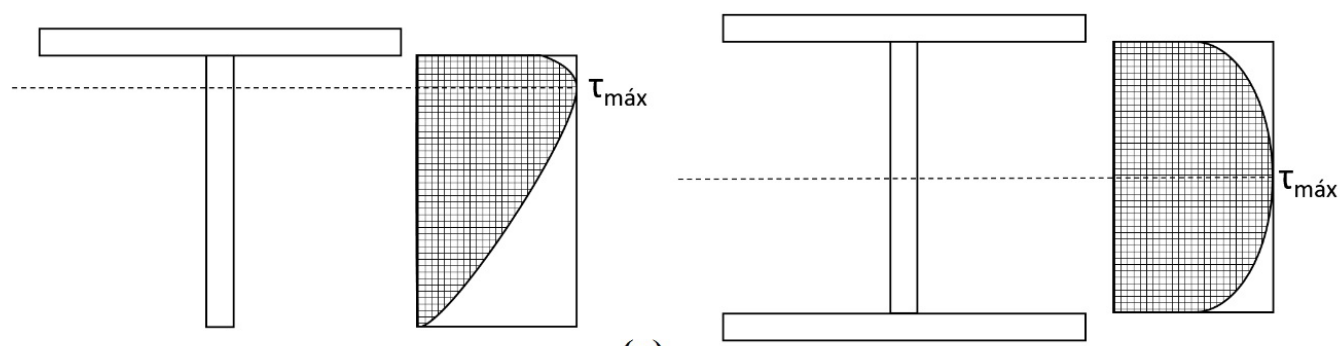

(a)
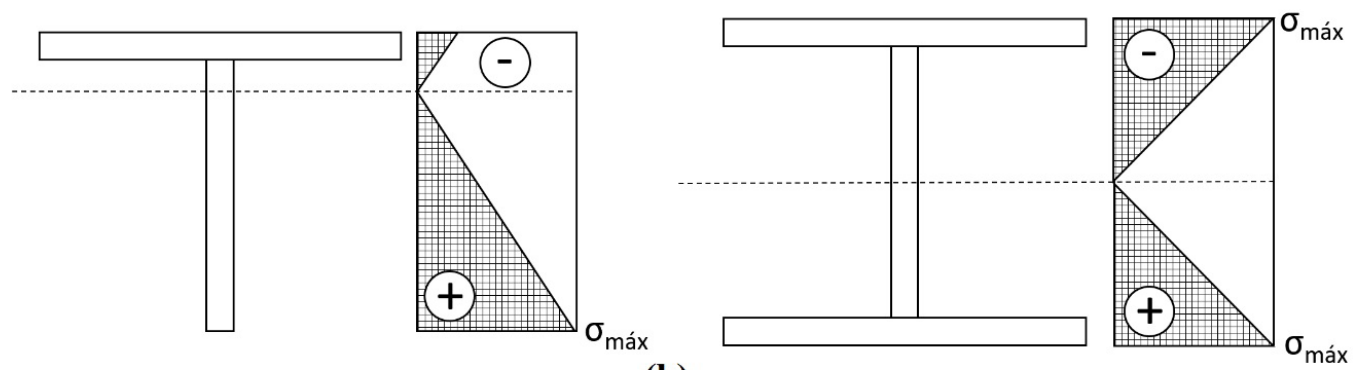

(b)

Figura 3. Distribuição de tensões de cisalhamento (a) e tensões normais (b).

onde a Equação 6 visa determinar a tensão máxima de cisalhamento " $\tau$ ", a partir de um esforço cortante " $V$ ", que para este caso particular (vigas bi-engastadas e carregamento pontual no centro da viga) corresponde à metade do valor do carregamento imposto " $\mathrm{P}$ ". A Equação 7 visa calcular as tensões normais máximas, oriundas dos esforços de flexão, a partir do momento fletor que a viga é submetida $\left(\mathrm{M}_{\mathrm{y}}\right)$, distancia do eixo neutro até a fibra mais externa da viga (" $c$ ") e momento de inércia (ou segundo momento de área) denominado por "I". O momento fletor máximo " $M_{y}$ ", na Equação 8, para este caso particular, é determinado em função do carregamento " $P$ " e do comprimento da viga " $\mathrm{L}$ ".

Ao substituir a Equação 9 na Equação 6 e Equação 8 na Equação 7, pode-se obter, para vigas com as seções propostas, e assumindo-se $\tau / \sigma=0,577$ (adotando-se a teoria da energia de distorção) o comprimento crítico da viga, onde $\sigma=\tau$, ou seja, para " $L$ " menores que este comprimento, as tensões são governadas por cisalhamento e para " $\mathrm{L}$ " maior que este comprimento crítico as tensões dominantes são governadas por esforços normais. Os valores são apresentados no subcapítulo 3.2 .

Tensões cisalhantes geralmente não representam um fator limitante no dimensionamento de vigas, exceto nos seguintes casos: a) a viga é muito curta, b) existem aberturas na alma da viga, c) a viga está sujeita à carregamento intenso e concentrado próximo aos suportes e d) a viga possui abertura para acesso de soldagem ("scallop") [2,16].

\subsection{Impacto estrutural}

Quando as deflexões são pequenas e os materiais são linearmente elásticos, pode-se estabelecer relações gerais entre cargas, deflexões e tensões em estruturas. Quando as deflexões são grandes, os materiais tornam-se não lineares e ocorrem efeitos dependentes do tempo, ainda assim para análise básica o comportamento de pequenas deflexões lineares ainda é adotado [20].

O comportamento da junta soldada e metal base foi avaliado através de perfil de dureza na alma e no metal de solda e através da deflexão final (flecha). Todos s perfis " $\mathrm{T}$ " e "I" foram engastados (soldados) em ambas as extremidades, e submetidos ao carregamento de impacto no centro da viga (Figura 4 (a, b)). Adotou-se um punção circular, disposto transversalmente à viga, de modo a concentrar o carregamento no centro da viga.

O martelo de queda possui uma massa de $245 \mathrm{~kg}$, enquanto o punção na extremidade possui massa de $22 \mathrm{~kg}$, perfazendo massa total de $267 \mathrm{~kg}$. O curso guiado desta massa até a viga é de $2.570 \mathrm{~mm}$. A velocidade no momento do impacto, foi medida em $6,69 \mathrm{~m} / \mathrm{s}$ e a aceleração durante a queda foi de $9,33 \mathrm{~m} / \mathrm{s}^{2}$. Adotou-se um acelerômetro analógico em conjunto com sistema de aquisição de dados com frequência de $1 \mathrm{KHz}$. A aceleração 


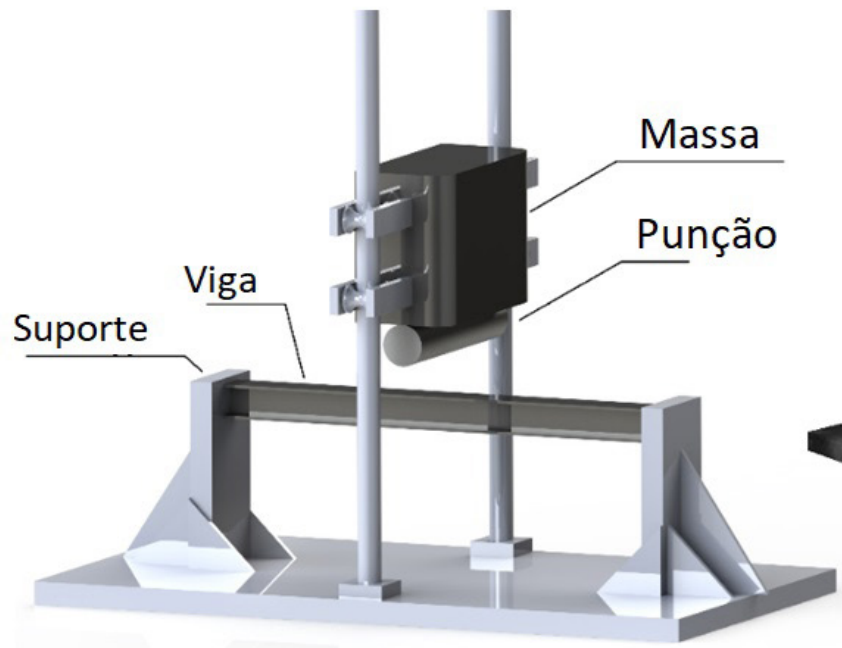

(a)

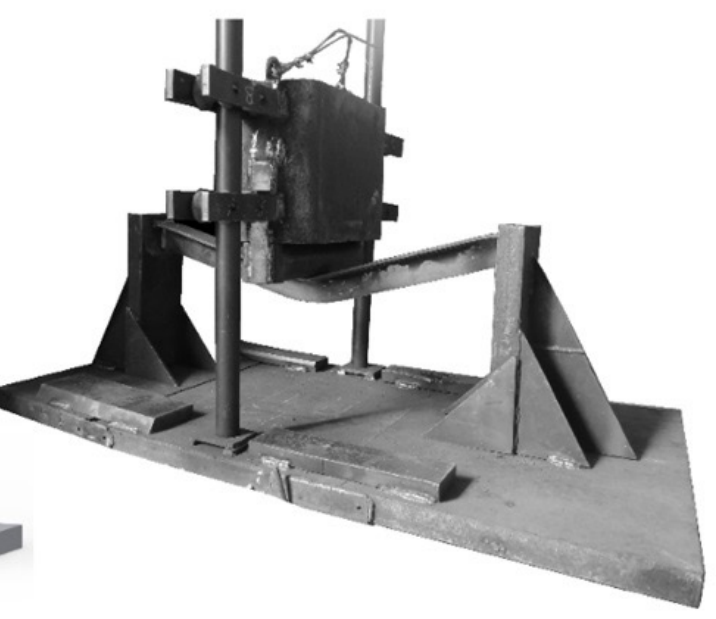

(b)

Figura 4. Elementos do Protótipo (a) e viga após ensaio (b).

inferior à da gravidade deve-se ao atrito entre guias e roletes. A velocidade de impacto obtida impõe uma taxa de deformação que pode ser classificada como teste de tração (ou compressão) dinâmico. Alta e hiper velocidade pode ser obtida somente através de barra de impacto e canhões de gás ou explosões, respectivamente [21].

As propriedades mecânicas e geométricas das vigas são mostradas na Tabela 3. É interessante ressaltar que um aumento de $57 \%$ na área da seção transversal (no caso de uma viga T para I) - e consequente aumento na mesma proporção de peso por metro - resulta em um aumento expressivo de 3 vezes a resistência ao momento fletor, conduzindo à uma relação peso / carga suportada muito mais favorável (tanto para as vigas curtas quanto para as vigas longas).

Tabela 3. Propriedades geométricas das vigas.

\begin{tabular}{|c|c|c|c|c|}
\hline & $\begin{array}{c}\text { Área da seção } \\
\text { transversal [mm²] }\end{array}$ & $\begin{array}{c}\text { Momento de Inércia } \\
{\left[\mathrm{mm}^{4}\right]}\end{array}$ & Fator de Forma & $\begin{array}{c}\text { Momento Plástico } \\
\text { [KN.m] }\end{array}$ \\
\hline Viga I 4,75 mm & 1.045 & $8,835 \times 10^{6}$ & 1,136 & 8,09 \\
\hline Viga T $4,75 \mathrm{~mm}$ & 665 & $2,569 \times 10^{6}$ & 1,779 & 2,64 \\
\hline Viga I 6,35 mm & 1.397 & $12,359 \times 10^{6}$ & 1,159 & 10,29 \\
\hline Viga T $6,35 \mathrm{~mm}$ & 889 & $3,554 \times 10^{6}$ & 1,790 & 3,39 \\
\hline
\end{tabular}

Fonte: Valores calculados a partir das fórmulas [14], Tabela 8.13 e Tabela A1.

\subsubsection{Fases do movimento de elevada massa}

Examinou-se a resposta plástica dinâmica de uma viga bi-engastada, de comprimento $2 \mathrm{~L}$, mostrado na Figura 5(a) quando atingido no comprimento médio por uma massa $M$ deslocando-se com velocidade $V_{0}$ no instante do impacto, enquanto o restante da viga permanece estacionário [22]. Então, duas fases distintas do movimento ocorrem. É importante introduzir o conceito de rótula plástica: enquanto $\mathrm{M}<\mathrm{M}_{\mathrm{p}}$ a viga se comporta elasticamente e obedece à lei de Hooke. Quando $M=M_{p}$ a viga começa a escoar, e deforma-se plasticamente. Neste ponto, a deformação aumenta sem que ocorra aumento das tensões, iniciando a formação de rótulas plásticas. Assim, pode-se definir rótula plástica como uma região que sofre grande deformação em um membro estrutural, e se comporta como uma rótula real. Geralmente se localizam (em uma viga) onde ocorre carregamento pontual, nos suportes e nos locais onde ocorre momento fletor máximo. A primeira fase consiste quando uma rótula plástica se desenvolve no local do impacto no instante $t=0$ e deste mesmo local, duas rótulas móveis propagam o distúrbio afastando-se do centro da viga e deslocando-se em direção aos suportes, mostrado na Figura 5(b) - ६é a localização da rótula plástica, é a velocidade de deslocamento desta rótula e corresponde à $\mathrm{V}_{0}$. As rótulas plásticas permanecem 
estacionárias nos suportes e no centro da viga durante a fase final de movimento (totalizando 3 rótulas plásticas), indicado na Figura 5(c), até o momento que viga e martelo permaneçam estacionários, quando toda a energia cinética da massa é dissipada plasticamente [20,22]. Esta rótula plástica é mostrada na Figura 6, mas também é notória a flambagem na alma da viga, neste caso de um perfil T, devido à tensão de compressão exercido na porção inferior da viga (e somente próximo ao suporte). Para o caso de martelos de queda com elevada massa, ao final da primeira fase do movimento (ou seja, quando $\xi=L$ ) prevê-se quando $M / m L ~>>1$ (onde " $M$ " é a massa do martelo, " $\mathrm{m}$ " é a massa da viga e " $\mathrm{L}$ " é o comprimento da viga). Ainda, a energia cinética a ser dissipada durante a segunda fase do movimento é dada por $M \cdot V_{0}^{2} / 2$ (quando $\mathrm{M} / \mathrm{mL}>1$ ), então (no início da segunda fase do movimento), assumindo-se que a perda de energia na primeira fase é desprezível. A partir destas observações, é mostrado que a primeira fase do movimento exerce pouca importância no caso de martelos de elevada massa [18,20,22]. Assim, a conservação de energia para a segunda fase do movimento, dada pela Equação 10, com o perfil de velocidades mostrado na Figura 5 (c), requer que:

$$
4 M_{p} \theta=M V_{0}^{2} / 2
$$

onde o primeiro membro da equação representa a energia necessária para que ocorra uma rotação $\theta$ junto ao suporte de uma viga com capacidade de resistir à um momento plástico $\mathrm{M}_{\mathrm{p}}$. O segundo membro $\left(M . V_{0}^{2} / 2\right)$ representa a energia cinética do martelo no momento do impacto. O deslocamento transversal final ("flecha" $-w_{f}$ ) é dado por

$$
w_{f}=(L-x) \theta
$$

onde $\mathrm{x}=0$ no centro da viga (flecha máxima) e $\mathrm{x}=\mathrm{L}$ exatamente no suporte (quando $\mathrm{x}=\mathrm{L}$, a flecha torna-se nula). Ao isolar $\theta$ na Equação 11 e substituir na Equação 10, obtém-se:

$$
w_{f}=M V_{0}^{2} L(1-x / L) / 8 M_{p}
$$

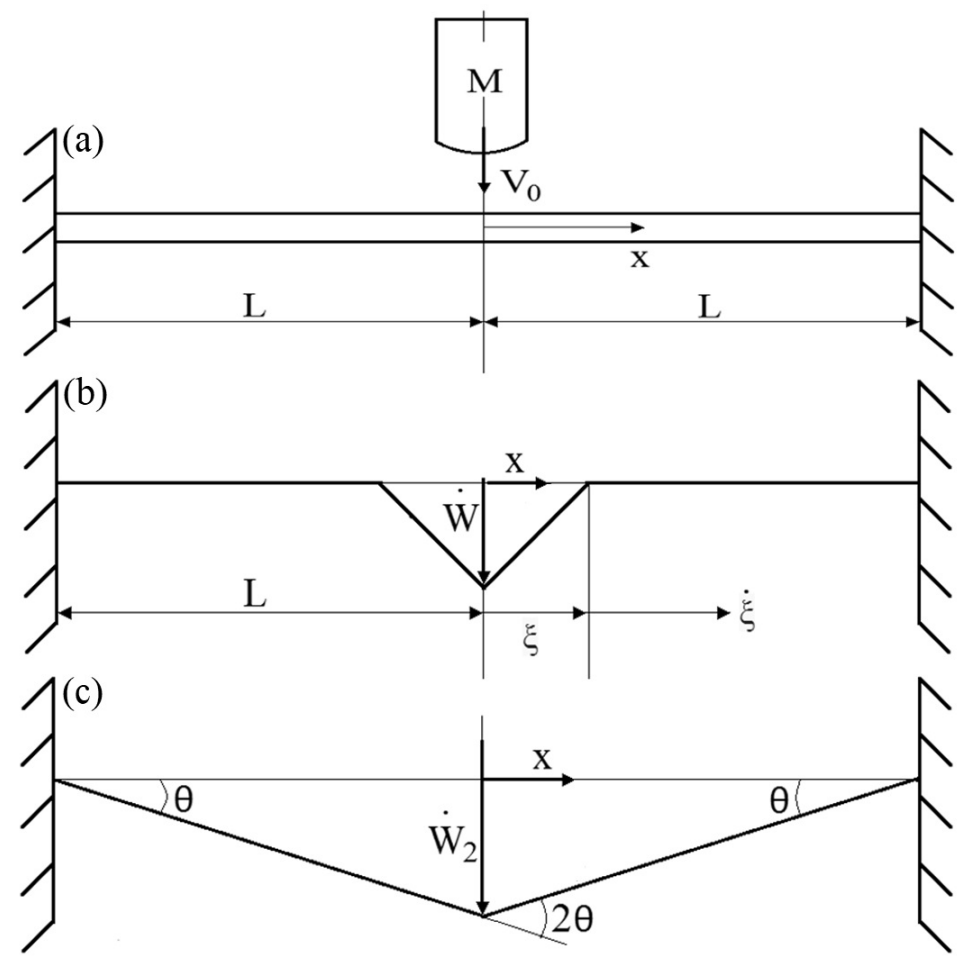

Figura 5. (a) Impacto de uma massa $M$ se deslocando à velocidade $V_{0}$ em uma viga bi-engastada; (b) $1^{\text {a }}$ fase do movimento: localização $(\xi)$ e velocidade $(\dot{\xi})$ da rótula plástica móvel; (c) 2a fase do movimento: $\dot{W}$ e $\dot{W}_{2}$ são as velocidades transversais no centro da viga. 


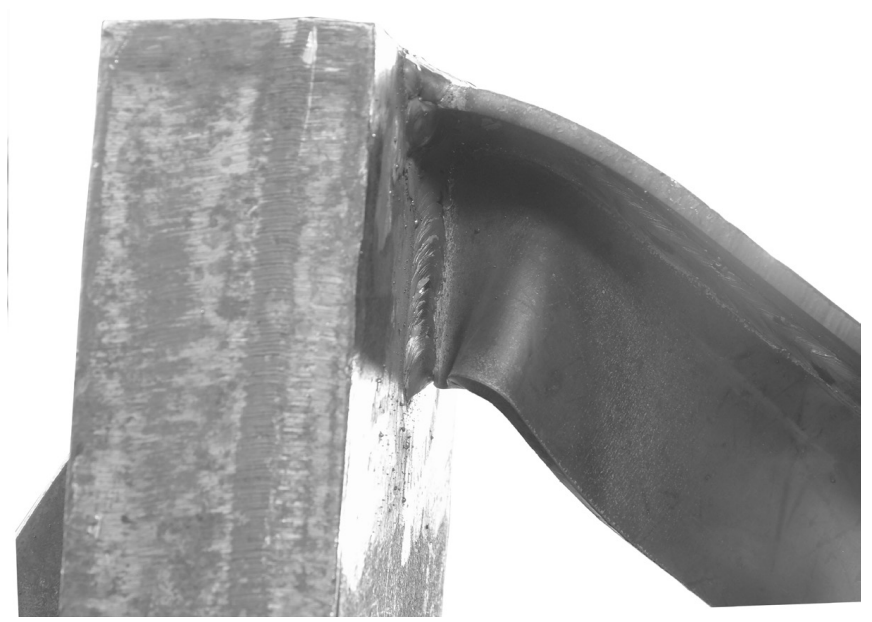

Figura 6. Flambagem da alma, junto aos suportes, presente em todos perfis T.

\section{Resultados e Discussão}

Rótulas plásticas móveis são encontradas em estruturas de espessura fina que falham por flambagem local. Como a deformação precede a flambagem, que por sua vez muda de forma, e isto envolve a mudança de local da rótula plástica. Na deformação estática de membros estruturais, as rótulas plásticas são estacionarias, porém rótulas plásticas móveis foram postuladas de modo a explicar a forma final (deformada) de membros estruturais sólidos submetidos ao impacto [20]. Este comportamento foi observado nos perfis "T" - Figura 6, devido à falta de restrição na seção inferior da alma da viga (vigas curtas e longas).

A flambagem da alma, junto aos suportes resultou em falha da alma da viga, na amostra CP \#2, viga longa Figura 7. A seção inferior da alma da viga, submetida à tração, escoou até romper. As durezas verificadas no metal de solda, na alma da vigas e o perfil de distribuição de durezas nas vigas I são apresentados respectivamente nas Figuras 8-10.

Em todas vigas I nenhum sinal de flambagem próximo aos suportes foi observado, apenas abaixo da linha onde o impacto ocorreu. $\mathrm{O}$ impacto resultou em flambagem lateral na alma, porém devido à sua maior resistência ao momento fletor e maior rigidez na porção inferior da viga (junto à mesa inferior), a energia remanescente não foi suficiente para causar o colapso da viga. Isto pode ser observado ao comparar os deslocamentos sofridos pelas vigas na Figura 11.

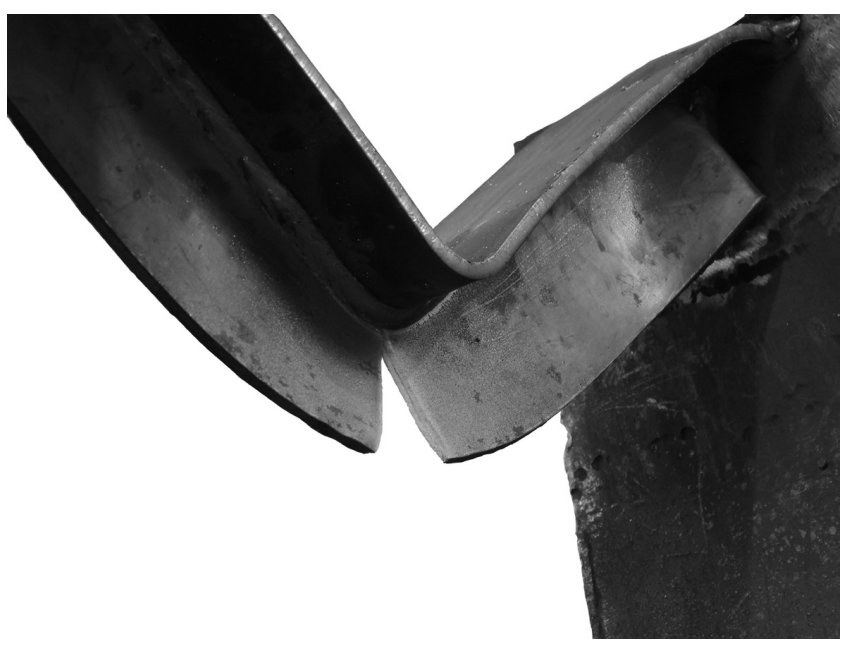

Figura 7. Ruptura da alma do perfil T por deflexão excessiva. 


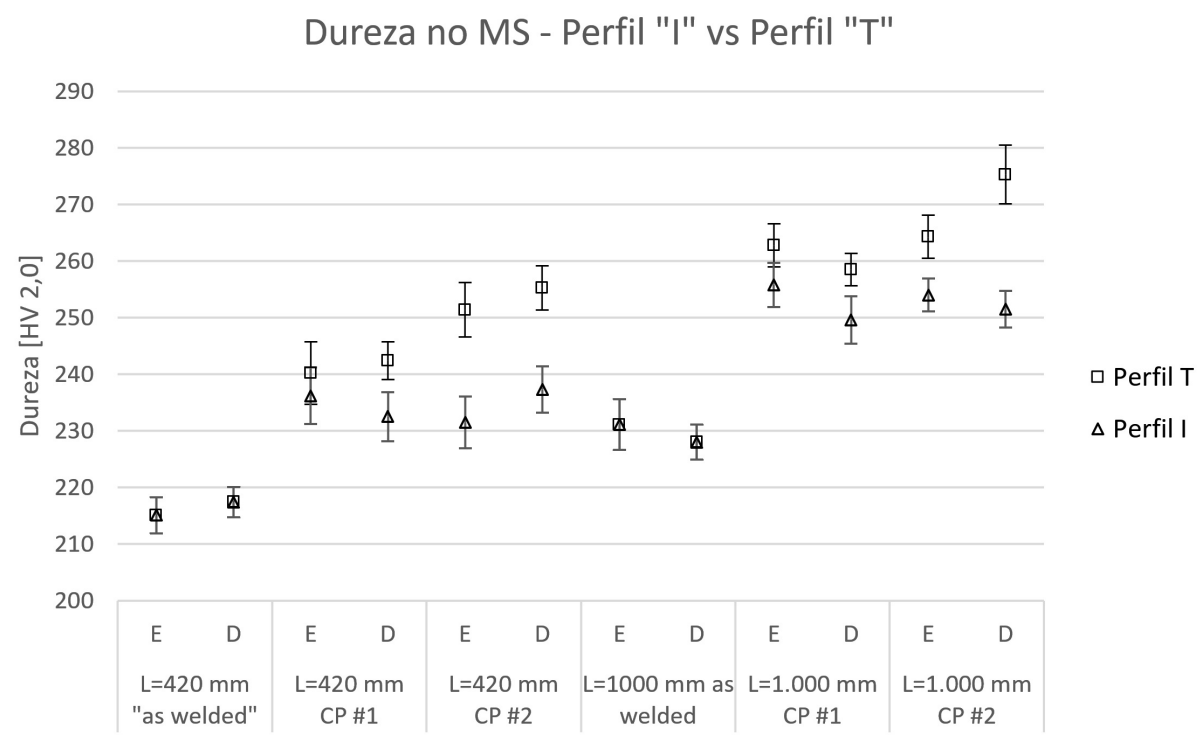

Figura 8. Dureza obtida no MS.

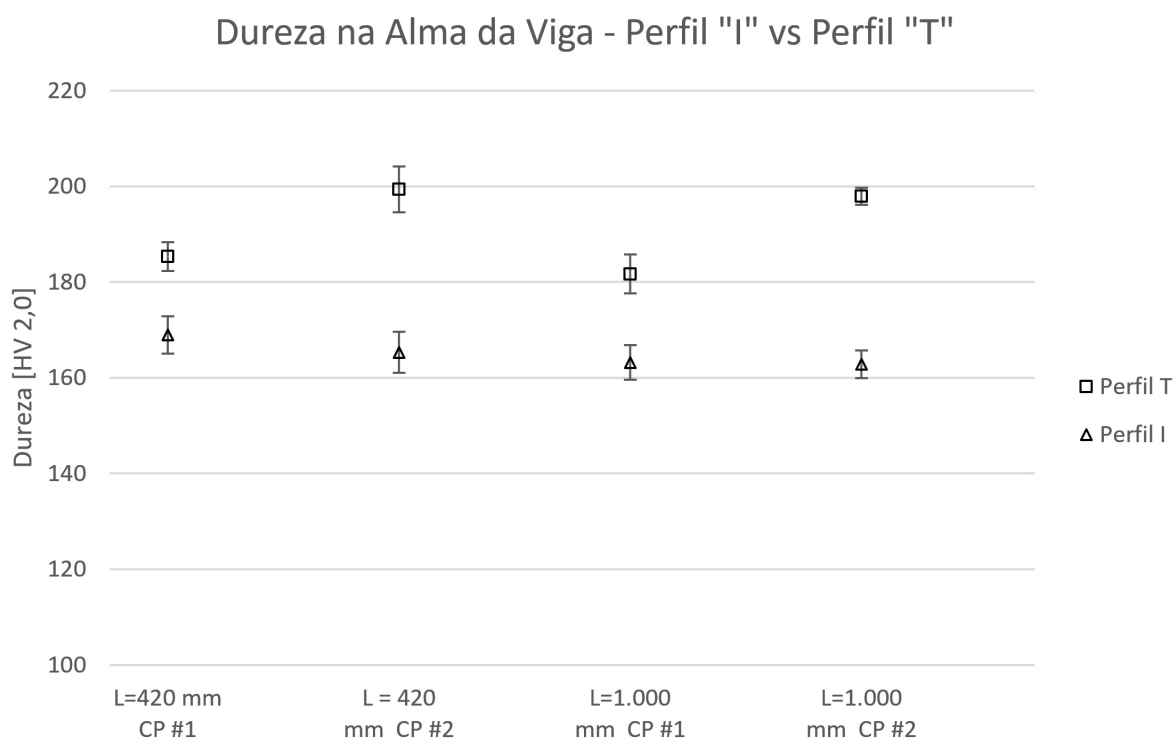

Figura 9. Dureza obtida na alma das vigas.

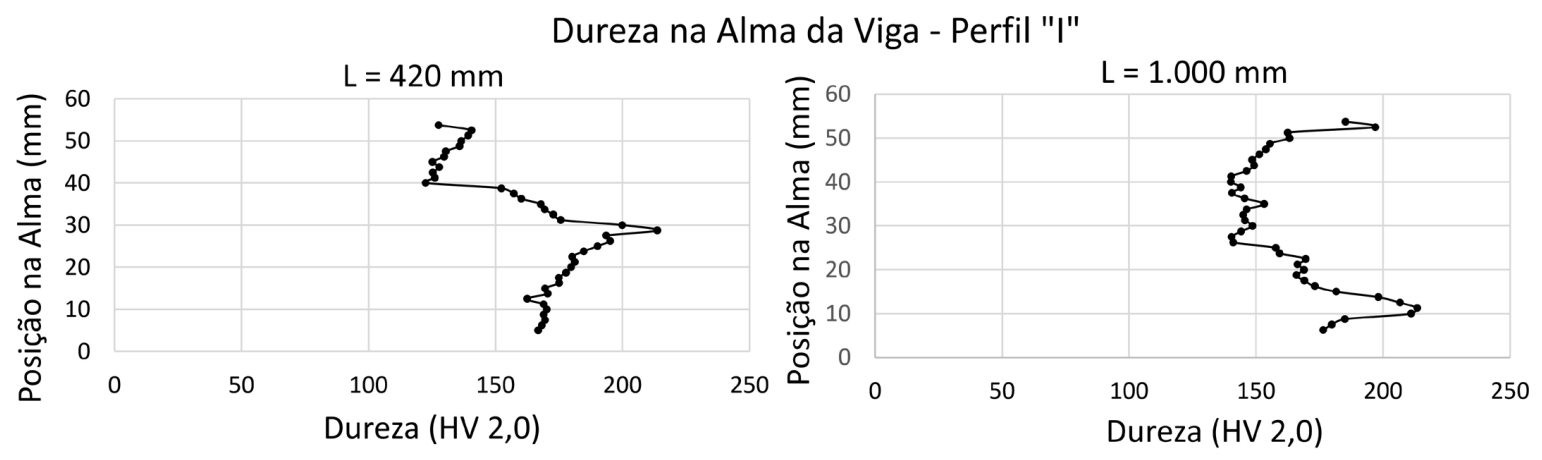

Figura 10. distribuição dos valores de dureza para o perfil I, viga curta (esq.) e viga longa (dir.). 
Deflexão das Vigas

250

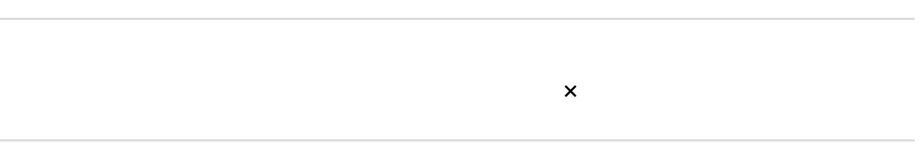

200

$\diamond$

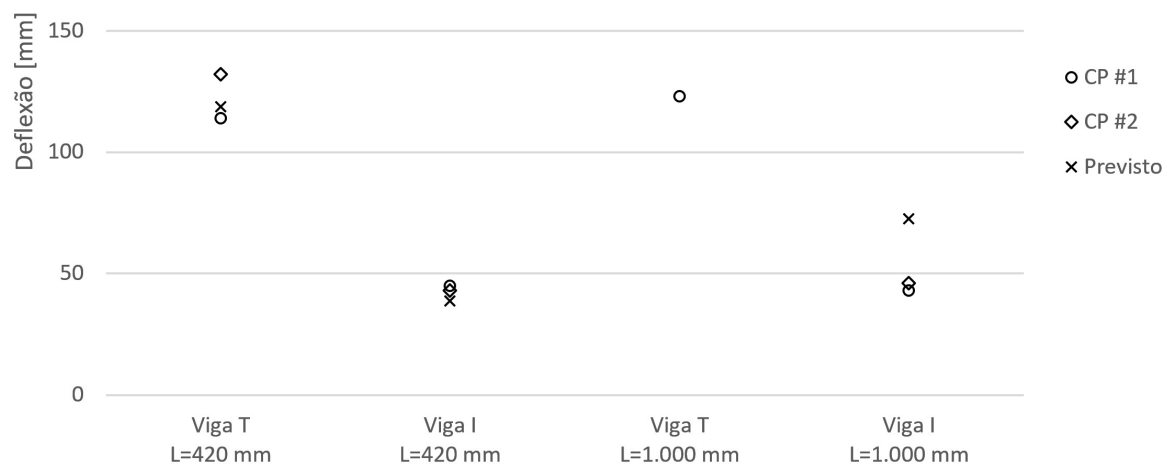

Figura 11. Deflexão final nas vigas após ensaio.

\subsection{Perfil de durezas no metal de solda}

O perfil de dureza no metal de solda foi verificado de acordo com a Figura 2, e os resultados mostrados na Figura 8, onde " $E$ " denota cordão esquerdo e " $D$ " cordão de solda do lado direito.

Ainda na Figura 8, observam-se maiores valores de dureza obtidos para os perfis T em relação aos perfis I, indicando que houve maior deformação (e posteriormente este resultado se mostra condizente com maior deslocamento transversal da viga - ver Figura 11). Ainda, deve-se salientar que os maiores valores (média e individual) de dureza foram obtidos da viga T longa CP \#2, a qual teve a maior deflexão e consequente rompimento na alma. Devido ao trabalho à frio, tensão de escoamento, limite de resistência e dureza aumentam, ao custo de redução no alongamento e ductilidade. Também chamado de encruamento, este fenômeno é explicado com base em interações entre as discordâncias e os campos de deformação. Em um metal, a densidade de discordâncias aumenta com a deformação ou trabalho à frio, devido à multiplicação destas ou formação de novas discordâncias. Consequentemente, a distância média de separação entre discordâncias diminui, ficando próximas entre si [23], desta forma aumentando a dureza do material.

\subsection{Perfil de durezas na alma da viga}

De acordo com o equacionamento proposto no cap. 2.4.2 (Equações 6 à 9), o comprimento crítico das vigas obtido foi de $170 \mathrm{~mm}$ para o perfil T e $595 \mathrm{~mm}$ para o perfil I. Comprimentos de viga inferiores ao comprimento crítico implicam em tensões governadas por cisalhamento, e comprimentos superiores resultam em tensões normais oriundas da flexão.

A verificação de dureza na alma dos perfis - Figura 9-mostrou resultados consistentes com aqueles obtidos na dureza do metal de solda e deflexão das vigas: valores maiores para os perfis T e inferiores para os perfis I. Pôde-se estabelecer uma relação do comprimento da viga e distribuição de durezas na alma, de acordo com a tensão dominante (Figura 3). Foi observado gradiente de dureza máxima nas extremidades e mínimo na linha neutra para as vigas longas, enquanto para as vigas curtas o máximo ocorreu no centro e o mínimo nas extremidades, conforme Figura 10. Verificou-se este comportamento somente nas vigas I, possivelmente devido à excessiva deformação imposta nas almas dos perfis T e ao comprimento crítico deste perfil ser muito pequeno (170 mm).

Este perfil de dureza obtida nas vigas "I" (menores valores no centro e máximos nas extremidades) aponta que ocorreu maior escoamento nestes pontos de dureza elevada, reforçando a probabilidade que as tensões que 
governaram os esforços foram as tensões normais (oriundas do momento fletor) - para as vigas longas, e nas vigas curtas as tensões dominantes foram oriundas do cisalhamento. [2,15,17].

Como mencionado anteriormente na seção 3.1, maiores valores de dureza - quando obtidos por trabalho à frio - refletem em maior resistência porém menor alongamento, isto significa que o ponto ocorre escoamento aproxima-se do ponto do limite de resistência do material, reduzindo também o alongamento total admissível [24]. Quando esta habilidade de se deformar é reduzida, isto pode resultar em ruptura súbita, causando colapso da viga. Entretanto, esta "ruptura súbita" é possível de ocorrer apenas quando a viga já tenha sofrido uma quantidade apreciável de deformação. A adoção de aços com menor razão tensão de escoamento / limite de resistência permite maiores deformações antes que ocorra instabilidade, permitindo também maiores descontinuidades ou entalhes presentes, devido à maior ductilidade [24].

\subsection{Deflexão transversal final}

Após os ensaios, cada viga foi removida dos suportes e teve a deflexão final ("flecha") medida exatamente no centro - onde atinge seu valor máximo. Os valores experimentais são mostrados na Tabela 4.

Tabela 4. Deflexão obtida experimentalmente [mm].

\begin{tabular}{|c|c|c|c|c|}
\hline & \multicolumn{2}{|c|}{$\mathrm{L}=420 \mathrm{~mm}$} & \multicolumn{2}{|c|}{$\mathrm{L}=1000 \mathrm{~mm}$} \\
\hline & CP \# 1 & CP \#2 & CP \# 1 & CP \#2 \\
\hline Perfil “T” & 114 & 132 & 123 & 184 \\
\hline Perfil “I” & 45 & 43 & 43 & 46 \\
\hline
\end{tabular}

Na Figura 11 é mostrada esta deflexão, tanto para os perfis "I" quanto para os perfis " $\mathrm{T}$ " e comparados com os valores previstos das Equações 11 e 12. Os valores previstos para as vigas curtas se mostraram muito próximos aos valores experimentais obtidos, porém para as vigas mais longas os valores previstos se mostraram superestimados. Cabe ainda salientar que que a deflexão prevista de $220 \mathrm{~mm}$ para o perfil T de $1.000 \mathrm{~mm}$ não reflete um valor realista. Na realidade, a viga T, CP \#2 rompeu com $184 \mathrm{~mm}$ de deslocamento transversal, assim a adoção de qualquer valor acima deste, não é necessariamente válido. Para efeito de comparação, para casos de construção civil, deflexões podem variar de $1 / 360$ até $1 / 240$ do comprimento da viga [16], e valores acima de 1/200 podem impossibilitar a operação de objetos móveis, como portas e janelas.

Os resultados teóricos e experimentais para uma viga carregada dinamicamente indicam que a sensibilidade à taxa de deformação do material é de fundamental importância e não pode ser desconsiderada, particularmente para deflexões maiores que a espessura estrutural [22]. Para vigas extremamente curtas, este efeito pode ser desconsiderado.

\section{Conclusão}

Quando vigas são carregadas dinamicamente, é provável que o efeito de sensibilidade à taxa de deformação aumente a capacidade de uma viga resistir à um momento $M$ (e consequentemente $M_{p}$ ). Isto se deve ao aumento nos valores de tensão de escoamento e limite de resistência [2]. Os valores de deflexões obtidos serem inferiores aos previstos apontam na direção deste efeito ter ocorrido (vigas longas).

Dentro dos limites experimentais do presente trabalho e de acordo com os resultados obtidos, as seguintes conclusões podem ser observadas:

- A dureza no MS aumentou proporcionalmente à deflexão da viga. Os maiores valores foram encontrados nas vigas $\mathrm{T}$;

- A dureza na alma da viga demonstrou que o padrão de escoamento seguiu o padrão de distribuição de tensões normais para as vigas longas (menores valores no eixo neutro e máximos nas extremidades superior e inferior), enquanto para as vigas curtas o padrão foi de tensões cisalhantes; 
- As equações adotadas de [20,22] forneceram valores superestimados, devido ao efeito da taxa de deformação e perdas de energia (principalmente calor da conformação mecânica e energia transmitida à base do equipamento);

- Pode-se desconsiderar o efeito de sensibilidade à taxa de deformação somente em vigas muito curtas, que dificilmente seriam adotadas na prática.

\section{Referências}

[1] Machado IG. Novos paradigmas para especificação de juntas soldadas. Soldagem \& Inspeção. 2012;17(3):278-288. http:// dx.doi.org/10.1590/S0104-92242012000300012.

[2] Pilkey WD. Formulas for stress, strain, and structural matrices. 2nd ed. Charlottesville: John Wiley \& Son; 2004. 1533 p.

[3] Sharp ML. Static and dynamic behavior of welded aluminum beams. Welding Journal. 1973;(Suppl):49s-56s.

[4] Parkes EW. The permanent deformation of an encastre beam struck transversely at any point in its Span. Proceedings of The Institution of Civil Engineers. 1958;10(3):277-304. http://dx.doi. org/10.1680/iicep.1958.2037.

[5] Mentel TJ. The plastic deformation due to impact of a cantilever beam with an attached tip mass. Journal of Applied Mechanics. 1958;25(4):515.

[6] Symonds PS, Bodner SR. Plastic deformations in impact of beams. In: Lee EH, Symonds PS, editors. Proceedings of The 2 nd Symposium on Naval Structural Mechanics; 1960; Providence. Providence: Pergamon Press; 1960. p. 488-500. https://doi. org/10.1016/B978-0-08-009459-5.50029-6.

[7] American Society for Testing and Materials. ASTM standard A36-14: standard specification for carbon structural steel. West Conshohocken: ASTM; 2014.

[8] Associação Brasileira de Normas Técnicas. NBR 6892: materiais metálicos - ensaio de tração à temperatura ambiente. Rio de Janeiro: ABNT; 2013.

[9] American Society of Mechanical Engineers. Boiler and pressure vessel code, section 2-c - specification for welding rods, electrodes and filler metals. New York: ASME; 2013. 926 p.

[10] American Welding Society. AWS D1.1: structural welding code - steel. Miami: AWS; 2015

[11] Elektriska Svetsnings Aktie Bolaget. Filler metal catalog [internet page]. Contagem: ESAB; 2016 [acesso em 17 Jan. 2016]. Disponível em: http://www.esab.com.br/

[12] American Welding Society. AWS A3.0: standard welding terms and definitions. Miami: AWS; 2010.

[13] American Society for Testing and Materials. ASTM standard E92-16: standard test method for knoop and vickers hardness of materials. West Conshohocken: ASTM; 2016.

[14] Chen W, Atsuta T. Theory of beam columns. 1st ed. vol. 2. New York: J. Ross Publishing; 2008. 753 p.

[15] Gere JM, Goodno BJ. Mechanics of materials. 7th ed. Canada Cengage Learning; 2009. 1022 p.

[16] American Institute of Steel Construction. AISC 360-05: specification for structural steel buildings. Chicago: AISC; 2005.

[17] Young WC, Budynas RG. Roark's formulas for stress and strain. 7th ed. New York: McGraw-Hill; 2002. 854 p.

[18] Szuladzinski G. Formulas for mechanical and structural shock and impact. 1st ed. Boca Raton: CRC Press; 2010. 790 p.

[19] Ketchum MS, Draffin JO. Strength of light i-beams. Illinois: University of Illinois at Urbana-Champaign Library; 1932. 241 p. (Engineering Experiment Station Bulletin; 241).

[20] Macaulay M. Introduction to impact engineering. 1st ed. Michigan: Chapman and Hall; 1987. 282 p.

[21] Dieter GE Jr. Mechanical metallurgy. 1st ed. New York: McGrawHill; 1961.646 p.

[22] Jones N. Structural impact. 2nd ed. United Kingdom, Cambridge University Press; 2012. 603 p.

[23] Callister WD, Rethwisch DG. Materials science and engineering: an introduction. 8th ed. Pensilvânia: John Wiley \& Sons; 2010. $1000 \mathrm{p}$.

[24] Machado IG. Falhas de estruturas de aço soldadas devido à reduzida ductilidade. Soldagem \& Inspeção. 2013;18(4):391403. http://dx.doi.org/10.1590/S0104-92242013000400011. 